\title{
PSYCHOLOGICAL CHARACTERISTICS AND MOTIVATION OF POTENTIAL FOSTER PARENTS: EXPERIENCE OF PSYCHOLOGICAL SUPPORT OF THE "SCHOOL OF FOSTER PARENTS"
}

\author{
Liliia Kazakova ${ }^{1}$, Anna Zakharova ${ }^{2 \star}$, Elena Lazareva ${ }^{3}$, Irina Chigineva ${ }^{4}$, Tamara Ta- \\ lanova ${ }^{5}$ \\ ${ }^{1}$ Chuvash State University, Russia \\ ${ }^{2}$ Chuvash State University, Russia, zaharova_an@mail.ru \\ Chuvash State University, Russia, \\ ${ }^{4}$ Medical and health resort in Cheboksary", Russia \\ ${ }^{5}$ Chuvash State University, Russia \\ ${ }^{*}$ Corresponding Author
}

\begin{abstract}
Currently, there is an acute problem of social protection of children left without parental care. Placement of a child in a foster family is associated with many different risks of a socio-psychological and medical nature, which can have a negative impact on the effectiveness of parenting and the mental health of children. In this regard, the implementation of psychological and pedagogical support for foster families becomes priority to create conditions for effective family education of foster children and careful selection of candidates for foster parents.

The article presents the results of a study of psychological characteristics and motivation of potential adoptive parents. The study involved 45 candidates for foster parents. In this study, the following methods have been used: questioning, an experimental psychological method, which included testing according to the psychodiagnostic methods by Oslon V.N. that are intended for psychological diagnostics of future adoptive parents. The results obtained indicate that there is a tendency towards different orientations of the motives of candidates for foster parents. Some candidates have a traumatic life experience, which can determine the destructive orientation of the motive for adoption, there is internal and external disharmony and conflict. Individuals with an orientation with an altruistic orientation of motivation have greater agreement in relations with others and internal conflict-freeness. Candidates for foster parents who have high self-esteem, self-respect, a positive attitude towards the family and parents have a high resource of effective upbringing of a foster child. It is proposed to divide candidates into groups in accordance with the characteristics of their psychological state and motivation, which prompted the decision to take parenthood when organising psychological and pedagogical support of the School of foster parents. Such a distribution can help the candidate to establish (or vice versa) the decision about parenting and give one the opportunity to realize the presence of one's traumatic experience. Individual counseling for each candidate can help to work out psychological trauma, become an important part of psychological and pedagogical support for host families, and reduce the psychological risks of "secondary orphanhood".
\end{abstract}

Keywords: motivation of potential foster parents, psychological characteristics of potential foster parents, "School of Foster Parents", traumatic life experience

\section{INTRODUCTION}

One of the global challenges around the world is the problem of orphanhood. So the issue of social protection of children left without parental care is especially relevant. Placement of a child in a foster family has a 
positive effect on one's emotional background, behavior, psychological and mental health. That is why it's important to carry the implementation of psychological and pedagogical support for foster families to create conditions for effective family upbringing of foster children.

The work is being carried out to prevent social orphanhood, to ensure a safe and secure childhood in the Chuvash Republic (Russian Federation). According to the Federal Data Bank of the Ministry of Education and Science of Russia, the number of orphans in the Chuvash Republic is decreasing annually (4503 people in 2012, 2862 people in 2019). The number has decreased by 1,640 children.

2850 orphans live in the republic according to information as of April 1, 2019, 2705 of children (94.9\%) are brought up in foster families. "Secondary orphanhood" also takes place when there is the return of children from foster families and families of guardians (trustees). In 2018, the decision to transfer 54 children to foster care was canceled. As of April 1, 2019, the decision to transfer 10 children to foster care was canceled (Federal data bank., 2019).

In recent years, cases of refusal of guardians, foster parents from their foster children have become more frequent (Makhnach A.V., 2015). This phenomenon has been called secondary orphanhood (Osipova I.I., 2008). Today it is a social phenomenon that has a negative impact on the psyche of a child. In this connection, it is relevant to study the factors, motives and personal characteristics of adoptive parents and the success of the upbringing of adopted children by these parents.

Foreign researchers focus their attention on the study of factors that influence the decision-making process regarding the legal adoption of children. Among the main reasons why Africans carry out the legal adoption of children are that it is legal, ensures the safety of parenting and all parental rights and responsibilities for raising an adopted child, psychological, alleviating the psycho-emotional pain of infertility (Gerrand P.A, Warria A., 2020). The relationship of religiosity with decisions made by families during adoption, strict discipline, parental stress and negative influence of parents is considered in the work of Helder E.J., Gunnoe M.L., Timmermans H. (2020). The study has found that families with a high religious motivation adopt older children and have large family sizes. Greater religious motivation is interconnected with stricter discipline and is not interconnected with parental stress or negative influence of parents on children (Helder E. J., Gunnoe M. L., Timmermans H., 2020). The next significant factor, researchers name is the degree of existential threat, which increases the desire of people for offspring. Awareness of one's own mortality increases the willingness to adopt children only when there is a belief that the child's personality is a product of upbringing and is determined by the parent himself. Existential influence increases the general readiness for adoption even in cases where potential parents cannot have biological offspring (Hoppe A., Fritsche I., Koranyi N, 2017).

Nowadays the studies are being conducted on the influence of the emotional and personal characteristics of candidates for adoptive parents on the effectiveness of raising adopted children and adaptation during the admission period, the characteristics of the adopted child and the difficulties in taking care of him. The factors influencing the dynamics of the development of relationships in the foster family, the formation of the level of psychological readiness for the upbringing of foster children, criteria for the resource capacity and viability of the foster family (Besschetnova O.V., 2013; Boenkina E.A., Krasnoryadtseva O.M., Shcheglova E.A., Bredun E.V., 2020; Bolshakova L.N., 2004; Gapchenko E.A., Kagermazova L.Ts., 2018; Gibadullin N.V.,2014; Kondratyeva N.I., 2008; Makhnach A.V., Laktionova A.I., Postylyakova Yu.V., 2015; Minevich O.K., 2009; Oslon V.N., 2006; Ushakova E.V., 2003; Yaparova O.G., 2009; Yevstratova Yu.V. 2013; Zhuikova E.B., Pechnikova L.S., 2014) are being considered.

Gapchenko E.A. separates subjective and socio-psychological factors in the system of psychological determinants of the resource of the substitute family. The author's subjective factors include the psychological characteristics of candidates for foster parents: the content of admission motivation, psychological readiness, emotional stability, self-attitude, empathy, the image of the future, the attitude to maintain close emotional contact. The socio-psychological author includes: the positive nature of interpersonal relationships in the family, optimal communication networks, the presence of supportive relationships, the constructive style of family education (Gapchenko, 2018).

Researchers identify factors that can increase or decrease the level of this readiness considering the psychological readiness for substitute parenting. Low motivation for approval and high communicative motivation contributes to an increase in psychological readiness, and high motivation to avoid failures and a low level of satisfaction with social support reduces psychological readiness (Boenkina E. A., Krasnoryadtseva O. M., Shcheglova E.A., Bredun E.V., 2020). The personality traits of mothers experiencing problems with raising foster children are often characterized by a high level of altruism. Foster mothers who have successful experience in socialization are dominated by material motives (Shcherbina S.M., 2015) and a common 
orientation of the personality (Markina O.A., 2016). The presence of family ties and the "empty nest syndrome" in this case may be the leading motivation for taking an orphan into foster care (Averyanova N.I., Khanova N.A., 2014).

The presented studies of decision-making factors in relation to the adoption of children, psychological readiness for substitute parenting and the successful experience of raising adopted children are somewhat contradictory and more often performed on a small group of candidates, which requires further clarification and study of this problem.

The aim of the study was to disclose the psychological characteristics and motivational orientation of candidates for foster parents.

The formulated goal led to the solution of the following tasks:

1. To study and analyze the personality traits of candidates for substitute parents from the point of view of the influence of psychotrauma on the candidate's motivational orientation.

2. To assess the severity of fears, a tendency to depression, feelings of self-guilt, conflicting relationships with parents, potential aggressiveness, dependence on other people's opinions, demonstrativeness, emotional rejection, signs of family disharmony among candidates for adoptive parents

3. To study the motivational orientation of candidates for foster parents.

4. To conduct a comparative analysis of the personal characteristics of adoptive parents who have psychotrauma and candidates who do not have it: fears, feelings of their own guilt, conflict relationships with parents, egocentrism, dependence on other people's opinions, emotional rejection, signs of family disharmony, attitude towards oneself, differentiation in relationships with loved ones.

A hypothesis of the study was put forward that the destructive motivational orientation of candidates for foster parents, determined by their desire to get rid of past traumatic situations of varying severity, increases the risk of repeated orphanhood.

\section{RESEARCH METHODS}

The empirical research was carried out on the basis of the Cheboksary Center for Orphans and Children Left without Parental Care of the Ministry of Education of Chuvashia. The study involved 45 candidates for foster parents who applied to the center. The age of the candidates has ranged from 27 to 61 years. 30 women and 15 men have taken place in the study.

In this study, the following methods were used: analysis of scientific literature, questionnaires, an experimental psychological method, which includes testing according to psychodiagnostic techniques by Oslon V.N. (Oslon V.N., 2013):

1. "Questionnaire of admission motivation" by Oslon V.N., which allows to identify the leading motives for adoption and their compliance with the criteria for the full development and effective upbringing of a child. The analysis of the results is carried out by highlighting constructive and insufficiently constructive types of motivation.

2. The "Incomplete sentences" method (by Sachs Levy) is aimed at diagnosing attitudes towards socially significant objects, revealing the hierarchy of values, revealing veiled, hidden and often unconscious sides of the problem.

3. "Family Sociogram" by Eidemiller E., Yustitskis V., allows to identify the position of the candidate in the system of interpersonal relations, attitude towards oneself and to determine the nature of communication in the family (direct, mediated). It has scales: mediated, unconscious negative attitude towards the father, towards the mother, emotional rejection, egocentrism, insufficiently differentiated attitude towards the family (diagnosed as negative or positive)

A mathematical-statistical method was used to process the results obtained, including descriptive statistics, Pearson's correlation analysis.

\section{RESULTS AND THE DISCUSSION}

The study of the motivation for adoption using a questionnaire on the motivation by V.N. Oslon made it possible to divide the candidates for adoptive parents under study into 4 groups. The results are shown in Table 1. 
Table 1. The results of the study on the questionnaire on the motivation of receiving by Oslon V.N.

\begin{tabular}{|l|c|c|}
\hline \multicolumn{1}{|c|}{ Motivation for admission } & $\begin{array}{c}\text { Number of people } \\
\text { (out of 45) }\end{array}$ & $\%$ \\
\hline Childless family (motive aimed at removing stigma) & 14 & 31 \\
\hline Acute grief (death or serious illness of loved ones) & 6 & 13 \\
\hline $\begin{array}{l}\text { Unsettled personal life (motive aimed at solving existential prob- } \\
\text { lems) }\end{array}$ & 8 & 39 \\
\hline "Good Samaritans" (child's altruism and self-worth) & 17 & 39 \\
\hline
\end{tabular}

Childless family (motive aimed at removing stigma). Out of 45 candidates for substitute parents, $14(31 \%)$ do not have, or for some reason cannot have children. Such candidates opt for the statements of the questionnaire that relate to a sense of duty, following God's will; cannot imagine life without children; express regret for not having a large family; often choose statements that the family must have children or cannot in any way give birth to children of the gender they need; believe that a family with a child commands respect from others; often friends and relatives advise to have their own children. They had unsuccessful IVF attempts and (or) spontaneous termination of pregnancy, they think that the adopted child will be their joy. The main motive of this group of candidates is aimed at removing the negative attitude towards the family, which cannot bear a child and is a "failure" in the eyes of society.

In the group "acute grief (death or serious illness of loved ones) six candidates for substitute parents (13\%) turned to adoption because of bereavement or worries about a serious illness of loved ones. This motive was determined by statements in which it was said that they felt the need to love someone and want to help another child who had lost too They choose the statements of the questionnaire that the candidate's child has a serious illness and that the adopted child will become a friend and will somehow be able to take care of their child when their (parents) are gone. The life has the meaning with a child, they say. These candidates are motivated by acute grief, devastation, persistently depressed mood and lack of positive emotions.

In the group "unsettled personal life (a motive aimed at solving existential problems)" 8 candidates (17\%) have an unsettled personal life or loneliness. They think that the child will become a family and dispel their loneliness, because relationships with the opposite sex do not work out, they believe that they have no choice, they also want a child, thinking that they will gain more respect in society. Those who are around them tell them that it's time to have their own child. Life with parents under constant pressure and criticism is difficult and leads them to think that the child will allow them to solve this problem and create their own family. The solution of existential problems (the meaning of life, the reasons for loneliness) is the motives of these candidates.

The group of candidates for foster parents who consider the child's intrinsic value to be the main one in adoption and who showed altruism in this regard was the largest - 17 people (39\%). Like a group of childless, they chose the adoption of a child as a duty of every person following God's will, but in combination with the following statements, their motive takes on a more altruistic orientation: someone has made a vow to God that they would bring up an orphan, someone has had more time to share it with an adopted child, someone has grown children and there are conditions to raise another. They agree with the assertions that a substitute family is a good way to help disadvantaged children, and love for children, having a friendly family will help raise an adopted child spiritually and morally healthy. In their opinion, any child, regardless of his state of health, behavior and academic success, is a great value in and of itself. For many, the main thing is children, allowing them to realize themselves as a person, to transfer experience and skills. There are candidates who are ready to accept a sick child and help him. We called this group the Good Samaritans.

Thus, analyzing the results of the questionnaire, it is possible to identify a tendency towards a destructive and constructive orientation of the motives of candidates for foster parents. One gets the impression that the 
first three groups are united by some kind of traumatic life experience, which determines the destructive orientation of the motive for adoption, while in the last group, the orientation of the motive acquires a more altruistic character and is constructive.

The analysis of responses using the Sachs Levy's "Unfinished Sentence" Methodology has allowed us to determine the psychological characteristics of candidates - fears that they perceive and are not aware of, feelings of guilt, relationships with parents, and self-acceptance (Table 2).

Table 2. The results of the diagnostic examination of candidates for substitute parents using the "Incomplete sentences" method by Saks Levy

\begin{tabular}{|c|c|c|c|c|c|c|}
\hline \multicolumn{7}{|c|}{ number of people } \\
\hline Motives & $\begin{array}{l}\text { Positive } \\
\text { attitude } \\
\text { towards } \\
\text { father }\end{array}$ & $\begin{array}{l}\text { Positive } \\
\text { attitude } \\
\text { towards } \\
\text { yourself }\end{array}$ & $\begin{array}{l}\text { Fears and } \\
\text { concerns }\end{array}$ & $\begin{array}{l}\text { Family } \\
\text { positive } \\
\text { attitude }\end{array}$ & $\begin{array}{l}\text { Positive atti- } \\
\text { tude towards } \\
\text { mother }\end{array}$ & $\begin{array}{l}\text { feeling of } \\
\text { guilt }\end{array}$ \\
\hline $\begin{array}{c}\text { Childless } \\
\text { (14 people) }\end{array}$ & 2 & 3 & 13 & 7 & 11 & 12 \\
\hline $\begin{array}{c}\text { Acute grief } \\
\text { (6 people) }\end{array}$ & 1 & - & 5 & 1 & 6 & 6 \\
\hline $\begin{array}{c}\text { Lonely } \\
(8 \text { people) }\end{array}$ & 3 & - & 3 & 2 & 7 & 4 \\
\hline $\begin{array}{c}\text { Samaritans } \\
(17 \text { people })\end{array}$ & 13 & 15 & 11 & 16 & 15 & \\
\hline
\end{tabular}

The main motive was to remove the negative attitude towards the childless family as inferior in the group "childless family". $86 \%$ of 14 people have a sense of guilt with negative connotations, relations with the father. Statements about the father are often colored with resentment.

Basically, all candidates have a positive attitude towards their mother, but $22 \%$ have statements colored with negative shades, $79 \%$ of candidates have a negative attitude towards themselves and $21 \%$ have an egocentric personality. Fears and concerns are experienced by $92 \%$ of respondents.

The second group of candidates who have suffered a bereavement or have worries about a serious illness of loved ones, have a negative attitude towards themselves with a feeling of guilt in $100 \%$. Almost all candidates - $83 \%$ have fears and concerns, have a negative attitude towards their family and $84 \%$ towards the father. But all 6 people have warm feelings for their mother.

All 8 candidates with existential problems experience some degree of self-rejection. Half have feelings of guilt. 6 people have negative statements about the family. But the majority of candidates in this group (62\%) have no fears or concerns. And almost everyone has a positive attitude towards the mother.

The last group of candidates with an altruistic orientation generally has a positive attitude towards their mother (88\%), their family (94\%), and themselves (88\%). $12 \%$ of the 17 candidates feel guilty, but $65 \%$ have various fears and concerns.

Thus, nevertheless, the first three groups have more negative attitudes towards the father, family and themselves. Mostly they experience various fears, fears and feelings of guilt. All this together creates the impression of internal and external disharmony, of a certain internal conflict among the candidates of these groups.

A group with an altruistic orientation, has a more positive attitude towards the father and family, accepts themselves and feels less guilt compared to other groups, which may indicate greater agreement in relations with others and an internal lack of conflict.

The projective methodology "Family Sociogram" by Eidemiller E., Yustitskis V. made it possible to reveal the position of the respondents in the system of interpersonal relations, attitude towards oneself and to determine the nature of communication in the family (Table 3 ). 
Table 3. The results of diagnostic examination of candidates for substitute parents according to the Sociogram method by "Eidmiller E., Yustitskis V.

\begin{tabular}{|l|c|c|c|c|c|}
\hline \multicolumn{7}{|c|}{ Sociogram (number of people) } \\
\hline & $\begin{array}{l}\text { Negative } \\
\text { attitude to- } \\
\text { wards father }\end{array}$ & $\begin{array}{l}\text { Negative } \\
\text { attitude } \\
\text { towards } \\
\text { mother }\end{array}$ & $\begin{array}{l}\text { Emotional } \\
\text { rejection }\end{array}$ & egocentrism & $\begin{array}{l}\text { insufficiently differenti- } \\
\text { ated attitude towards } \\
\text { family members }\end{array}$ \\
\hline $\begin{array}{l}\text { Childless } \\
(14 \text { people) }\end{array}$ & 12 & 3 & 10 & 3 & 9 \\
\hline $\begin{array}{l}\text { Acute grief } \\
(6 \text { people) }\end{array}$ & 4 & 5 & 1 & 5 & 8 \\
\hline $\begin{array}{l}\text { Lonely } \\
(8 \text { people) }\end{array}$ & 7 & 7 & 8 & 7 & 4 \\
\hline $\begin{array}{l}\text { Samaritans } \\
\text { (17 people) }\end{array}$ & - & - & 1 & 2 & \\
\hline
\end{tabular}

In the "childless family" group of candidates, as in the previous method, 12 people (85\%) have negative attitude towards their father. $72 \%$ of the respondents have the experience of emotional rejection. $64 \%$ of candidates in this group have a symbiotic relationship in the family.

Among the respondents who experienced acute grief, $67 \%$ were focused on relationships, feelings and emotions. A high percentage of egocentrism is found (83\%).

$100 \%$ of candidates experiencing existential problems have insufficient differentiated attitude towards family members and they all feel emotional rejection (100\%), combined with egocentrism (87\%).

In the fourth group - the "good Samaritans", a low percentage was obtained for all the scales of this method. In comparison with other groups of respondents $6 \%$ have a rather low feeling of emotional rejection, $77 \%$ are quite differentiated in relation to their family members. $12 \%$ respondents have egocentricity. According to this method, there is a complete acceptance of the father and mother.

Thus, according to this technique, it is possible to conclude that the fourth group of candidates is more harmonious and has fewer psychological problems than all three others.

Conclusion and results according to the groups.

After processing all the results obtained using psychodiagnostic techniques, the following psychological characteristics of each group were identified:

1. A group of candidates "childless family". The socially approved priority - a family with a child or several children - is unfeasible for many childless families, and, as a rule, leaves the sign of failure and "otherness" on the spouses. Not everyone can remain in this situation of "social failure". Most childless spouses, when deciding to accept a child into their family, solve exactly this problem - to become "like everyone else", "ordinary" - that is, socially approved people and spouses. The child's psyche in this case bears the weight of the neurosis of the adoptive parents and, perhaps, is unable to adapt to this. The situation is aggravated by the apparent inability of the adoptive parents to effectively communicate with the child. These childless couples lack emotional flexibility, the ability to positive manipulation, and empathy. Both factors - the desire for social success without taking into account the opinion and psychological mood of the child and the lack of experience in communicating with children - lead to a rather high risk of returning the adopted baby back to the institution.

2. The second group of candidates "acute grief" (death or serious illness of a child or a loved one). All candidates for adoptive parents from this group have fears for various reasons, a sense of guilt. The available psychological characteristics can create a very dangerous negative atmosphere for the adopted child, the main feature of which will be the projection of the traits of the deceased child onto the child adopted into the family. Such a situation is not constructive and leads to mutual coldness of family members, their isolation from each other, and misunderstanding. Another important point is a depressive state, which, as a rule, is present in a parent who has lost a child, which cannot but affect the psyche of an adopted child. Lack of physical and mental resources in a depressed parent, emotional isolation in relation to all manifestations of life in general, and to an adopted child, in particular - this is an incomplete list of destructive features of depression. In this case, the 
adopted child feels rejected and unnecessary, not understanding what caused such an attitude towards him. The risk of returning the child to the institution in this group is more often than in the other two groups.

3. The third group of candidates "unsettled personal life" (a motive aimed at eliminating the existential threat). All candidates for adoptive parents from this group have a persistent rejection of themselves, 6 of them combine this quality with a negative attitude towards the family. All have emotional rejection. Personal disorder, most likely associated with unresolved psychological problems of adolescence, low self-esteem, which was stimulated by emotional rejection in the family (usually from the mother), indicates future problematic options for the development of the family. There is a clear risk that the future adopted child will develop practically the same psychological triggers as the adoptive parent - low self-esteem, self-rejection, negativistic attitude towards family values in general and towards the family as an institution of marriage, in particular. There is also a rather high risk of not finding a common language with the child, and accordingly, the risk of "secondary orphanhood" is quite high here.

4. "Good Samaritans" (altruism and self-worth of the child). 14 candidates have a positive attitude towards their father and 14 have a positive attitude towards their mother. 16 have a positive attitude towards themselves and their family. According to the "sociogram" method, there is no negative attitude towards father and mother. Since harmonious personality traits - such as altruism, mercy and the ability to deep compassion and respect for someone else's personality (in our case, this is the self-worth of the child) - are present in all candidates of this group, that is, there is a high probability of successful, effective interaction between the child and such parents. Their psychological and educational resource is large enough, which steadily reduces the risk of misunderstandings, quarrels and the imperative style of raising a future adopted child. Accordingly, the risk of returning a child to an institution for orphans is minimized in this group.

The Pearson correlation coefficient was calculated for all possible data pairs. Correlation analysis revealed statistically significant relationships.

The presence of a positive correlation between the scale "attitude to oneself" to the scale "status" ( $r=0.38$; $p<0.05)$ and to the scale "attitude to the family" $(r=0.46 ; p<0.01)$, shows that the higher a person's selfesteem and self-esteem, the less he feels "emotional rejection" $(r=-0.40 ; p<0.01)$ and the more harmonious relations in the family, with parents are ("negativ attitude to the father" $r=-0.51 ; p<0.01$, " negativ relation to the mother $r=-0.41 ; p<0.01$ ). The presence of independence and responsibility of these people is indicated by a rather high negative correlation between the scales "undifferentiated attitude towards family members" and "attitude towards oneself" $(r=-0.59 ; p<0.01)$.

Within the results of the "Good Samaritans" group, statistically significant correlations were revealed: the presence of self-esteem (scale "positive attitude towards oneself") positively correlates with relationships with parents $(r=0.43 ; p<0.01)$ and care for them $(r=0.49 ; p<0.01)$, and harmony in the family ("status" scale) is interconnected with positive self-esteem ("positive attitude to oneself" scale) $(r=0.43 ; p<0.01)$.

Thus, candidates for foster parents who have high self-esteem, a positive attitude to the family, to parents, in our study, this group of "good Samaritans", have a high resource of effective upbringing of a foster child and, as a result, the risk of "secondary orphanhood" is reduced.

The negative correlation relationship between the scale "undifferentiated attitude to family members" and the scale "attitude to the family" $(r=-0.31 ; p<0.05)$ indicates that dependence can be expressed in a negative attitude towards loved ones, to the family, to parents (negative attitude to the father $r=0.38 ; p<0.05$, negative attitude to the mother $(r=0.35 ; p<0.05)$ with a positive correlation to the same scale "undifferentiated attitude to family members") and the greater the feeling of "emotional rejection" ( $r=0.44 ; p<0.01)$ and egocentrism $(r=0.33 ; p<0.05)$.

In the "childless" group, perhaps due to their position, candidates for adoptive parents who had not experienced the experience of upbringing and responsibility for their own children showed a significant statistical positive relationship between the "egocentrism" scale and the "positive attitude to oneself" scale $(r=0.58$; $\mathrm{p}<0.01$ ), which may indicate an overestimated self-esteem and an overestimation of one's capabilities, although at the same time the feeling of emotional rejection is also greater $(r=0.33 ; p<0.05)$. The more pronounced egocentrism, the less connection with significant loved ones (scale "positive attitude to mother" $r$ = $0.58 ; p<0.01$ ). Overestimated self-esteem (scale "egocentrism") in the group "unsettled personal life" also negatively affects the acquisition of inner harmony (scale "status" $(r=-0.65 ; p<0.01)$ and on mutual understanding with parents (scale "positive attitude to the father $r=-0.49 ; p<0.01$ ).

In the group of candidates "acute grief", where the expectation or loss of a loved one contributes to an increase in the feeling of fear and apprehension, can lead to emotional dependence (scale "undifferentiated attitude to family members" $r=-0.63 ; p<0.01)$ but also more egocentricity $(r=0.63 ; p<0.01)$. 
A feeling of emotional rejection, disharmony and conflict negativity present in relation to the family, to parents, to oneself may indicate the presence of consequences of some kind of traumatic situations of varying degrees of severity in candidates for foster parents. In this work, these characteristics are inherent in the other three groups of respondents in varying degrees of severity. It can be concluded that children who find themselves without parental care, who are brought up in a substitute family of the "risk group", have a high probability of repeated orphanhood due to the psychological problems of their adoptive parents.

Analysis of the results of an empirical study of the motives and influence of the traumatic experience of candidates for adoptive parents on their decision to adopt a child into a family allowed us to draw a number of conclusions:

1. Of the entire sample, $61 \%$ of candidates had a prerequisite (i.e, the main motivation) for the decision to adopt a child into a family, trauma of various periods of limitation. In this case, the child is a "psychotherapeutic" factor capable of curing the consequences of trauma. The presence of psychotrauma is a destructive effect that increases the risk of "secondary orphanhood".

2. An unprocessed "acute psychotrauma" does not allow the development of parental competencies and creates an unfavorable microclimate in the foster family and increases the risk of the child returning to a boarding school or orphanage.

3. Based on the analysis of the data obtained, the respondents were divided into 4 groups according to the leading motives, and a tendency towards a destructive and constructive orientation of these motives was revealed. The analysis of the indicators of the following methods - "Unfinished sentence" and "Family sociogram" approved the direction of motivation of all four groups.

The study revealed a tendency towards destructive behavior of candidates for foster parents in the following groups: groups 1 ("Childless family"), 2 ("Acute grief") and 3 ("Unsettled personal life"). Moreover, in the Acute Grief group, we believe that the risk of a child returning to an institution for orphans is higher than in the other two groups. This conclusion was made after analyzing the psychological characteristics of all candidates in this group, and revealed depressive tendencies in them, which cannot positively affect the harmony in the foster family and require psychotherapeutic intervention.

The second in terms of risk was the group "Unsettled personal life", where the main psychological sign was rejection of oneself and family, as well as the fact that they had emotional rejection in their lives. Such a combination forms a clearly reduced self-esteem of the candidate and, as a result, the inability to give the child harmonious relationships, love, acceptance and effective communication.

The third in terms of the severity of the risk of "secondary orphanhood" was the "Childless family" group - due to such psychological characteristics as inability to communicate with a child, lack of emotional flexibility, ability to positive manipulation, empathy. At the same time, childless couples have a desire and high abilities, as a rule, for psychological learning and can, "with a high will to win", become successful smart parents.

The fourth group "Good Samaritans" have constructive tendencies in the upbringing of an adopted child, which distinguishes them from the other three groups. The child's altruism and self-worth, as well as a sincere desire to help the child, can reduce the risk of the child returning to a minimum. Candidates for adoptive parents who do not have psychotraumas have a high probability of resourceful and effective upbringing of an adopted child.

When organizing the psychological and pedagogical part of the School for adoptive parents, it is necessary to divide the candidates into groups in accordance with the characteristics of their psychological state and the reasons that prompted the decision on parenting. Such distribution in a delicate way can help the candidate to establish (or vice versa) in his decision to parenthood and give him the opportunity to realize the presence of the traumatic experience.

Individual counseling for each candidate can help work out psycho-trauma, as well as formulate the goal and objectives of psychological and pedagogical support for host families.

\section{REFERENCE LIST}

Averyanova, N.I., Khanova, N.A. (2014). Social portrait of foster families and ways to improve their medical and pedagogical support. Problems of social hygiene, health care and the history of medicine, vol. 4. 
pp. 15-18.

Besschetnova, O.V. (2013). The problem of orphanhood in modern Russian society: institutional aspects: dis. ... doc. sociol. sciences. SPb.

Boenkina, E.A., Krasnoryadtseva, O.M., Shcheglova, E.A., Bredun, E.V. (2020). Motivational modality as a predictive characteristic of psychological readiness for substitute parenting. Siberian Psychological Journal, vol. 75. pp. 145-158.

Bolshakova, L.N. (2014). Socio-psychological adaptation of parents and children in the foster family: diss. .... cand. of psychol. sciences. Yaroslavl.

Federal data bank on orphans and children left without parental care URL.: http://www.usynovite.ru/experience/bankpraktik/chuvashskajarespublika/ (treatment date 10.05.2019).

Gapchenko, E.A. (2018). Psychological characteristics of candidates for foster parents in the context of the risks of a modern family. Abstract of diss. candidate of psychol. sciences, 2018.

Gapchenko, E.A., Kagermazova, L.Ts. (2018). The study of the psychological characteristics of candidates to become foster parents in terms of risks modern family. World of Science. Pedagogy and psychology, [online] 5(6). Available at: https://mir-nauki.com/PDF/74PSMN518.pdf (in Russian).

Gerrand, P.A., Warria, A. (2020). Factors that motivate African women in South Africa to depart from kinship care to legal adoption of non-kin children //Southern African Journal of Social Work and Social Development. T. 32. vol. 2. pp. 1-18. doi: 10.25159/2415-5829/6537

Gibadullin, N.V. (2014). Motivation for the adoption of orphans and children left without parental care into a foster family. Basic research. vol. 9 (Part 12). pp. 2756-2759.

Helder, E.J., Gunnoe, M.L., Timmermans, H. (2020). Religious motivation to adopt as a predictor of adoptive family structure, parental discipline, and outcomes. Adoption Quarterl,T.23. vol. 3. pp. 163-186. doi.org/10.1080/10926755.2020.1790451

Hoppe, A., Fritsche, I., Koranyi, N. (2017). Self-transcendence as a psychological parenthood motive: When mortality salience increases the desire for non-biological children. European Journal of Social Psychology, T. 47. vol. 4. pp. 488-500. https://doi.org/10.1002/ejsp.2218

Kondratyeva, N.I. (2008). On the problem of family forms of raising orphans and children left without parental care and their psychological and pedagogical support. Siberian Psychological Journal, vol. 28. pp. 4548.

Makhnach, A.V. (2015). Psychological diagnostics of candidates for foster parents. The problem of orphanhood in modern Russia: psychological aspect. Moscow: Institute of Psychology RAS.

Makhnach, A.V., Laktionova, A.I., Postylyakova, Yu.V. (2015). The role of family resources in the selection of candidates for foster parents. Psychological journal, T. 36. vol. 1. pp. 108-122.

Markina, O.A. (2016). Motivation of the personality of the parent of the adopted child. Historical and socioeducational thought, 8 (2-2), pp. 106-111.

Minevich, O.K. (2009). Socio-psychological conditions for adaptation of children in foster families: dis. ... cand. psychol. sciences. Tambov.

Osipova, I.I. (2008). The phenomenon of secondary orphanhood in modern Russia. Bulletin of the Vyatka state. University, Kirov. vol. 4. pp.138-143.

Oslon, V.N. (2006) Living arrangements for orphans: professional foster family. M.: Genesis, 2006.

Oslon, V.N. (2013). Psychodiagnostic complex «A practical guide to conducting a psychological examination of citizens who want to adopt children for upbringing in their families». M .: Education.

Shcherbina, S.M. (2015). Analysis of the personal characteristics of women with experience of interaction with foster children. Prospects for Science and Education, vol. 1 (13).

Ushakova, E.V. (2003). Socio-psychological capabilities of the foster family as a rehabilitation structure for orphans: diss... cand. of psychol. sciences. M.

Yaparova, O.G. (2009). Socio-psychological determinants of successful adoptive parenting: author. dis. ... cand. psychol. sciences. M. 
Yevstratova, Yu.V. (2013). Research of the motivation for admitting a child to candidates for foster parents Mental deprivation of children in difficult life situations: educational technologies of prevention, rehabilitation, support. M.

Zhuikova, E.B., Pechnikova, L.S. (2014). Psychological characteristics of motivation for raising a foster child in the family. Psychological science and education, T. 19. vol.4. pp. 46-53. 